\title{
El abate Molina, la viruela... y también Darwin
}

\author{
The Abbe Molina, the smallpox... and also Darwin
}

Walter Ledermann Dehnhardt ${ }^{1}$

'Centro de Estudios Humanistas Julio Prado.

Recibido: 6 de noviembre de 2020

\section{Resumen}

Nuestro Abate Molina, nacido en Talca en 1740, debió hacer toda su notable carrera de naturalista en la Universidad de Bolonia, al ser expulsada de Chile la Orden Jesuita en 1767. En su juventud contrajo la viruela en 1761, enfermedad que lo tuvo a las puertas de la muerte, debiendo sufrir tanto por el virus como por los médicos y sus crueles e inútiles tratamientos, que incluyeron sangrías, enemas y "vinagre de los cuatro ladrones", de todo lo cual ha dejado constancia en dos "Elegías Latinas de la Viruela", de las cuales comentamos un puñado de versos de escaso valor literario pero de alto interés histórico. En una de sus últimas publicaciones esbozó algunas ideas evolucionistas, antecediendo en 44 años a la teoría de Darwin, siendo acusado de herejía y sometido a un juicio religioso que puso prácticamente fin a su carrera.

Palabras clave: Abate Molina, viruela, De peste variolarum, Darwin.

\section{Ignatii Molinae, pencopolitae}

$\mathrm{H}$ oy en día en Chile, gracias a la aniquilación sistemática de las humanidades en la enseñanza media, muy pocos conocerán al otrora célebre abate Juan Ignacio Molina, quien fuera un hombre de múltiples inquietudes intelectuales: teológicas, científicas, filosóficas y artísticas. Si bien nació en Chile en 1740, por haberlo hecho en Talca, cerca de Concepción, se autodesignaba en su juventud como talco-pencopolitae y no como chileno. Habiendo entrado a la Orden Jesuita, donde obtuvo una tremenda formación científica, la expulsión del país de esta congregación, ordenada por la corona de España en 1767, lo obligó a trasladarse a Italia, primero a Imola, donde llevó una existencia precaria, y luego a Bolonia, en cuya universidad desarrolló la mayor parte de la obra que le diera fama mundial.

Esta destacada carrera académica en Italia estuvo favorecida tanto por sus grandes y diversos conocimientos, como por hablar, aparte del

\section{Correspondencia a:}

Walter Ledermann D.

oncemayor@gmail.com

\begin{abstract}
The Chilean Abbe Ignacio Molina (1740-1829 ) developed a brilliant career as naturalist in the University of Bologna, where he arrived when the Jesuit Order was expelled from the Spanish colonies in 1767, until he was accused of heresy because some ideas about evolution expressed in one of his late works, at the same time with Lamarck and 44 years before Darwin. In his youth Molina was affected in a severe way by smallpox, leaving us in two poems a vivid story of his suffering, not only by the disease itself but also for the useless therapeutic measures, some disagreeable, like enemas; other injurious, as bleeding and topic vinegar of the four thieves. A handful of the more significant verses from the two Latin Elegies "De peste variolarum" and "De peste variolis vulgo dicta" is analyzed: its literary value is scarce, its reading is bored, and its real merit only historic.

Key words: Abbe Molina, smallpox, De peste variolarum, Darwin.
\end{abstract}

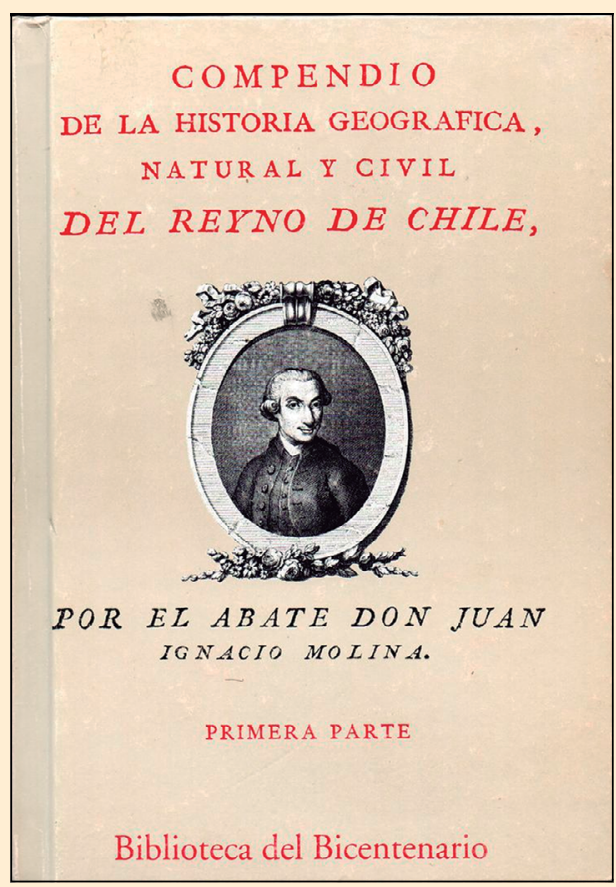

Compendio de la Historia Geográfica Natural y Civil del Reyno de Chile. Obra capital del Abate Juan Ignacio Molina. 
Recordemos que fueron los conquistadores españoles los que trajeron esta peste a América, como lo narra el cronista González de Marmolejo:

"Francisco de Villagra, que desembarcó en La Serena, parecía venir pronosticando al reino mal agüero, $i$ que de su venida les habia de venir mal en general a todos, porque en desembarcando se inficionó el aire de tal manera, que dio en los indios una enfermedad de viruelas, tan malas que murieron muchos, de toda suerte que fue una pestilencia mui dañosa... ${ }^{5}$. Y remata Diego de Rosales, definiéndola como una pestilencial enfermedad, tan contagiosa y pestifera, que apenas hay quien se escape de ella; que quita a muchos la vida i el que escapa es mui bien señalado y acrevillada la cara de oyos ${ }^{6}$.

La venganza de los indígenas del imperio inca, entre los cuales se contaba buena parte de los naturales chilenos, fue la fiebre de Oroya, que permitió a la Bartonella darse un festín con los conquistadores españoles: como dice el principio base del comercio, "pasando y pasando", tus viruelas y mi fiebre 7 . Pero adelantémonos al siglo XVIII, cuando moraba en Chile nuestro poeta, y recurramos a Enrique Laval para que nos cuente qué pasaba entonces con la viruela alrededor de 1761, año de la publicación de las Elegías:

"En 1759 se impuso una cuarentena en la isla Quiriquina a la fragata "Soplo de Lero", que venía del Callao y que durante la travesía había tenido varios casos de viruela. Y sigue el Dr. Laval contando que en 1760 el navio Begonia fue también aislado en esa isla y sus enfermos atendidos en el lazareto que dirigía el fraile juandediano José Eyzaguirre", incidente en que nos parece encontrar al probable culpable del brote que abatió al abate, quien enfermó el primero de mayo de 1761, cayó en cama el tres y sólo vino a levantarse el veintiuno.

$\mathrm{Y}$, a mayor abundamiento, "el 7 de julio de 1762 llegó a Coquimbo el navio "El valdiviano”, con varios enfermos de viruela; se aisló en La Herradura y los enfermos fueron llevados a un rancho lejano y se hicieron fumigaciones con litre o carachamaye. Finalmente, en 1789 hubo una gran epidemia de viruela en la ciudad de Concepción ... y el Protomedicato indica el secuestro de los enfermos, propone fumigaciones generales de la ciudad y de las casas y preconiza el uso del vinagre de los cuatro ladrones"

Este vinagre de los cuatro ladrones nos deja perplejos, no menos que el empleo de la leche de vaca, animal que también participaba en las procesiones y rogativas religiosas, como cuenta el escritor Augusto Orrego Luco: "en las Actas del Cabildo de Santiago se encuentra que en los casos de epidemia se hacian rogativas y se ordenaba que trajeran a Santiago todas las vacas de los alrededores para pasearlas por la ciudad... ¿con qué objeto?...¿¿qué relación había entre las vacas y la detención de la epidemia?" 9 . 


\section{Las Elegías Latinas del Abate Molina}

Las Elegías Latinas fueron dos: la primera "De peste variolarum" o "Sobre la peste y los variolosos", y la segunda "De peste variolis vulgo dicta" o "Sobre la peste comúnmente denominada las viruelas". En su exhaustivo estudio, el doctor Jaramillo nos cuenta que originalmente los dos libros contienen seis elegías cada uno, el primero con los síntomas de la peste, la visita del médico y la eucaristía, la sangría, el enema, los temores y la vigilia; en tanto que el segundo comprende los temas fiebre, sed, delirios, tubérculos (pápulas), hambre y salud. Ahora bien, como dedicara su obra al padre Javier de Irarrázabal, encargándole de paso su corrección, éste se excedió y le "arrebató" de su lecho el "borrador", corrigiéndolo a tal punto que en una segunda y extensa edición de 1767 hay más mano suya que de Molina; y para mayor complicación, al citar el texto de las distintas elegías, mezcla el doctor Jaramillo en su estudio versos de la primera y de la segunda edición (de la cual sólo existen fragmentos), método que también seguiremos para mayor facilidad del lector. Los originales de la primera edición están disponibles en el Archivo Nacional Santiago ${ }^{10,11}$, pero quien piensa hallar en ellos poesía hará bien en no buscarlos, porque en este arte nuestro héroe no era muy diestro y, en suma, son una buena lata, con un valor puramente histórico y médico.

\section{Los lamentos del enfermo}

Pero escuchemos al enfermo, quien debe su vida a un cirujano y farmacéutico alemán, el jesuita Wanckermann, quien lo arrebató de las manos del Protomédico de Santiago don Ignacio de Jesús Zambrano, que lo estaba matando con la medicina "oficial". Este Wanckermann no estaba reconocido en Chile como médico, por lo cual tanto él como su paciente faltaron a la ley, pero más vale ilegal vivo que legalista muerto:

Tal vez hubiera perecido de pena,

antes que la peste me hubiera cogido con garra mortal, si a tiempo Wanckermann no hubieras llegado...

Tú, a mí, que ya temblaba bajo la guadaña fatal solicito arrancaste de la tiesa garra de la muerte.

Sin duda habría muerto de fiebre furiosa, entre atroces gemidos

si tu compasión no me arranca del atroz suplicio.

Veamos ahora su interesante descripción de la viruela:

Una prodigiosa enfermedad, salida de las cavernas de la Estigia, me invadió el cuerpo, sin tener compasión conmigo.
Primero la cabeza, luego el resto de los miembros, advierten los sintomas del mal que se avecina. El estómago, inseguro, se retuerce en vómitos frecuentes. no puede relajarse, no logra descanso alguno.

Los ojos se oscurecen, pues ven caer la luz,

la lengua se reseca, los labios se entorpecen.

El calor la espalda abrasa: no tolera el ardor.

Vacila el pie y el cuerpo apenas se mueve débilmente.

Agrada el agua y luego desagrada;

alimentos cocidos son resistidos:

Las vísceras los piden y luego los vomitan. Furiosa la fiebre

oprime el vientre, generando triste miedo por doquier

El primer médico que lo atiende, el ya mencionado Zambrano, no queda muy bien parado :

Pregunta lo que siempre dicen los médicos, qué cómo ve, qué sufre y soporta, si le duele el vientre, si la cabeza atormenta, si la espalda arde...

Tomadas las manos, examina ambos pulsos y con ojo huidizo da un augurio desastroso:

Peste-afirma-es horrible, lo demuestra la fiebre muy alta. Ante todo que el enfermo se prepare a la ayuda celestial y sin demora reciba el sagrado viático del cielo.

En la tercera elegía del Libro I, Phlebotomía, se queja del estúpido y criminal uso de la sangría por los médicos de la época, indicada por el doctor Zambrano y practicada por un barbero indígena:

Es atroz la mirada del indio, su voz imperiosa y feroz, sin compasión la mano cruel y todo él barbarie.

Casi nada veo, me hace horribles llagas.

Salta sangre inocente manchando mi cara se torna negro el brazo, púrpuras los pies.

Al flexor de las venas disgusta todo tajo

y en la mayoría de las veces resulta evidente su nocividad.

En Lima y por esos mismos años Juan del Valle Caviedes, fino poeta, escribía mejor sobre el tema, pues casi lo mata un médico a puras sangrías:

En cuantas partes dijere "Doctor" el libro, estés atento, porque alli has de leer "verdugo", aunque éste es un poco menos.

Donde dijere "sangria", has de leer "degüello"

$y$ "cuchillo" leerás donde dice "medicamento"

Donde dijere "purgas" leerás "dio fin al enfermo"

$y$ donde "remedio" dice, leerás "muerte sin remedio"

A continuación, en la cuarta elegía, se queja otra abominable e inútil medida terapéutica, que aumenta sus molestias y le resulta humillante: el enema. 
Pero, en fin, no hay mal que dure cien años y el enfermo mejora. Siente "un límpido rocío: una lluvia de ambrosía y amapolas"; duerme noche y día al ceder la fiebre; al despertar el enantema bucal empieza a desaparecer y la pústulas se secan:
Admirado veo entonces los pálidos tumores secos ya del todo o a punto de estarlo pronto. Cada vez me molesta menos el odioso paladar, soportan las entrañas el fuego de la sed. Ninguna parte de los miembros rígida está, no están aletargados ni en inmovilidad: blandos ya, cumplen su servicio de costumbre.

Pero entonces otra necedad médica lo ataca, pues en plena recuperación siente un hambre invencible y en respuesta le aplican un régimen miserable, tanto que debe robar comida:

Está presente el sombrío custodio, más cruel que los osos, Más espantoso que Arpía: todo me arrebata.

Si le pido mucho, el impío lo niega con rostro severo si le pido poco lo niega también.

Mucho alimento guarda él bajo llaves de hierro, mucho pan encierra su cofre de fuerte madera.

En fuente pequeña, dos veces al día, me alimenta de insípido modo.

Entristecido el cielo se compadeció de mi esfuerzo: Olvidó el custodio cerrar y a escondidas me levanto sin temor alguno. Tomo la llave con mano temblorosa y abro: robo los panes que quiero.

Habiendo cumplido quince días en cama y sobrevivido a los tratamientos médicos y a la peste, se levanta tambaleante, pero sano. Está lleno de costras y cicatrices, pero feliz de ver el cielo y las vecinas montañas:

Recibi muchas heridas también en los miembros expuestos, marcas que porto en todo el cuerpo.

La cara y las manos exhiben mil cicatrices, otras mil escondes discretamente los vestidos. En la cara llevo pintadas manchas oscuras: la inicua peste me quiso con ellas marcar, a fin que al correr de los años

a nadie niegue que fui de su propiedad.

\section{El vinagre de los cuatro ladrones}

Al paciente se le aplicó el famoso "vinagre de los cuatro ladrones", que era el medicamento de elección en la colonia, persistiendo su uso por más de tres siglos. En efecto, en la versión española de un célebre Diccionario Enciclopédico de Medicina y Cirugía de 1891, el profesor 
Isidoro de Miguel y Viguri nos cuenta que "los vinagres oficiales de la farmacopea española son el de alcanfor, el antiséptico, el aromático inglés, el cólquico, el de los cuatro ladrones, el de escila, el de rosas, etc". En el mismo capítulo señala que el vinagre así diluido se usa "al interior" en las enfermedades febriles inflamatorias y en otras acompañadas de calor y sed intensas, en afecciones hemorrágicas y en las escorbúticas con tendencia a la sepsis, como los tifus, la fiebre puerperal, la pioemia y los exantemas (¿como la viruela?); así como sedante contra la excitación nerviosa y las excitaciones sexuales intensas... y al interior casi para todo, como cauterizante, exfoliativo, y etc, etc. ${ }^{13}$.

Siempre en este diccionario, en el capítulo de viruela se nos confirma lo narrado por Molina que al "desecarse las pústulas los enfermos quedan más tranquilos, duermen mucho y se les desarrolla un apetito intenso, que puede satisfacerse sin limitación". Agrega que los médicos antiguos usaban diaforéticos, eméticos y purgantes y ahora la quinina, todos sin utilidad demostrada; $y$ rechaza, igualmente, la aplicación sobre las pústulas los “toques repetidos con pincel de viruelas, especialmente en la cara, con tintura de yodo, nitrato argéntico y sublimado", proponiendo el uso de xilol, pero al vinagre ya no lo menciona ${ }^{14}$.

\section{¿El abate Molina precursor de Darwin?}

En sus últimos años en Bolonia, el abate escribió dieciséis Memorias de Historia Natural, una de las cuales es de interés médico o, más bien, biológico, la titulada "Analogías menos observadas de los tres reinos de la naturaleza", escrita en 1815 . Se ha postulado que esta obra, publicada al mismo tiempo que la de Lamarck y 44 años antes que la teoría de la evolución de la especies de Darwin, convertiría al abate Molina en precursor de ésta, tanto así que en 1968 la Universidad de Bolonia y la Academia de las Ciencias de Bolonia lo reconocieron como "precursor del evolucionismo biológico". El profesor Jaramillo sostiene que Molina habría planteado "con más de un siglo de antelación a Teilhard de Chardin, una teoría sobre la unidad evolutiva de la naturaleza y de la vida", apoyándose en estas palabras del abate: las producciones de la naturaleza forman un todo, único en el designio y variable en la ejecución, para mantener su proceso gradual... Habría, por lo tanto, "unicidad" de los seres de los tres reinos -mineral, vegetal y animaluna gradación establecida por la naturaleza entre sus productos, que va siempre creciendo en perfección, desde la ínfima planta criptógama hasta el más perfecto de los animales, como es el hombre.

Según el abate, los filósofos antiguos habrían establecido como una verdad fundamental que la naturaleza no procede por saltos, no pudiendo existir ninguna distin- ción absoluta "entre los seres creados; que todos están conjuntamente encadenados por recíprocos vínculos, de modo que existe entre ellos una progresión gradual, en virtud de la cual los minerales llegan insensiblemente a vincularse con los vegetales, y estos, con los animales"

Como en todo hay expertos, también los hay en Molina y éstos difieren en si el abate anticipó o no las ideas de Lamarck y de Darwin, desde los que consideran su teoría "todavía más amplia y avanzada que la de ambos", hasta los más parcos, que hablan sólo "de una teoría original y trascendente sobre la evolución biológica", para terminar con don Francisco Encina, el célebre historiador chileno, quien lo acusa de superficialidad, de "querer verlo todo, sin profundizar nada, como buen criollo hispano americano" 15

Haciendo presente que no hemos leído estas "Analogías menos observadas", no nos parece que esta frase, muy general, apoye la teoría de la evolución; en todo caso su contenido fue considerado herético por uno de sus discípulos, de apellido Ranzani, y el autor sometido a un sumario religioso que duró varios años y le causó no pocas contrariedades. A pesar de ser absuelto, se le solicitó diferir la publicación del manuscrito, que sólo en 1821, cuando el abate estaba ya en descrédito y había perdido muchos alumnos.

Prudentes y admiradores de Darwin, nosotros nos abstenemos.

\section{Referencias bibliográficas}

1.- Memoria Chilena. Biblioteca Nacional de Chile. El abate Juan Ignacio Molina (1740-1829). http://www. memoriachilena.gob.cl/602/w3-article-590.html.

2.- Reynaldo Charrier R y Hervé F. El Abate Juan Ignacio Molina: una vida dedicada a la Historia natural y civil del Reino de Chile. Revista de la asociación Geológica argentina 2011; 68 (3): 445-63.

3.- Jaramillo R. La más importante obra poética juvenil del Abate Juan Ignacio Molina: Elegías latinas de la viruela, 1761. Ediciones Nihil Mihi, Santiago de Chile, 1976.

4.- Alone. El Mercurio, Santiago, 18 de marzo de 1973.

5.- Capitán Alonso de Góngora Marmolejo. Historia de Chile desde su descubrimiento hasta el año de 1575 y seguida de varios documentos. En: Colección de Historiadores de Chile y Documentos relativos a la Historia Nacional. Tomo II. Historia de Góngora de Marmolejo (1536-1575). Imprenta del Ferrocarril, Santiago 1862. http://www.memoriachilena. gob.cl/archivos2/pdfs/MC0009045.pdf. http://www. memoriachilena.gob.cl/archivos2/pdfs/MC0009045.pdf.

6.- Diego de Rosales. Historia general del reino de Chile. Flandes Indiano (1674). Publicada por Benjamín Vicuña Mackenna. Imprenta de El Mercurio, Santiago 1878; vol. II.

7.- Ledermann W. Bartonella. En: Una historia personal de las bacterias. Editorial RIL, Santiago 2007; 177-86.

8.- Laval E. Notas históricas sobre la viruela en Chile. Rev Chilena Infectol, Edición Aniversario 2003; 109-10. 
9.- Orrego Luco A. La patria vieja. Prensas de la Universidad de Chile, Santiago 1933. http://www.memoriachilena. gob.cl/archivos2/pdfs/MC0050335.pdf. http://www. memoriachilena.gob.cl/602/w3-article-55644.html.

10.- Io (annis) Ignatii Molinae, pencopolitae. De peste Variolarum. Manuscrito autógrafo de 20 páginas, 622 versos. Archivo Nacional Santiago, Fondos varios, vol. 158.

11.- Io (annis) Ignatii Molinae, chilensis. De pestis variolis vulgo dicta. Manuscrito autógrafo de 29 páginas, 964 versos. Archivo Nacional Santiago, Fondos Varios, vol. 995: 64-78.

12.- Caviedes JV. Diente del Parnaso. Publicada en 1873 por Ricardo Palma a partir del manuscrito original de la
Biblioteca de Lima. En: Vicuña Mackenna, B. Médicos de antaño. Editorial Difusión, S.A., Santiago 1947; pp. 141143.

13.- Eulenburg A. Diccionario enciclopédico de medicina y cirugía prácticas, traducido directamente y arreglado para uso de los médicos españoles por el Dr. Isidoro de Miguel y Viguri. Sánchez de Jubera Hermanos, Editores. Madrid 1891; XIII: 471-5.

14.- Ibid; XIII: 484-518.

15.- Encina FA. Prólogo. La renovación de nuestra historia, una odisea literaria. En: Espinosa, J. El Abate Molina, uno de los precursores de Darwin. Zig-Zag: 7-63, Santiago 1946. 